\title{
AUTO-REGULAÇÃO EMPRESARIAL COM INSTRUMENTO DE GESTÃO AMBIENTAL NA UNIÃO EUROPÉIA
}

\section{BUSINESS SELF-REGULATION AS A TOOL FOR ENVIRONMENTAL MANAGEMENT IN THE EUROPEAN UNION}

\author{
Viviane Passos Gomes"
}

\begin{abstract}
Resumo: A responsabilidade de preservar o meio ambiente não pode mais ser encarada como uma obrigação tão somente do Estado, cabe também ao setor empresarial, incluso por ser uma dos maiores causadores da degradação ambiental, buscar soluções adequadas para internalizar o custo sócio-ambiental gerado por sua produção. Nos últimos anos vem crescendo a adesão de empresas aos instrumentos voluntários de gestão ambiental no âmbito da União Européia, principalmente com adoção de sistemas como o EMAS e a ISO 14000, que combinam esforços no sentido regular inclusive questões que não estão normatizadas na legislação ambiental vigente.
\end{abstract}

Palavras-chave: Auto-regulação empresarial. Gestão ambiental. União Européia.

\begin{abstract}
The responsibility to preserve the environment can no longer be seen simply as an obligation of the State. It is also the responsibility of the business sector, mainly for being a major cause of environmental degradation, to seek appropriate solutions to internalize the social and environmental costs generated by their production. In recent years there has been a growing adherence of businesses to voluntary instruments of environmental management within the European Union, especially with the adoption of systems such as EMAS and ISO 14000, which combine efforts to regulate even matters that are not included in the current environmental legislation.
\end{abstract}

Key-words: Self-regulation. Environmental management. European Union.

\section{INTRODUÇÃO}

Se por um lado a industrialização trouxe maior bem estar e conforto para o ser humano, por outro, o crescimento econômico empresarial engendra um processo apropriatório cada vez mais intenso dos recursos naturais.

O Poder Público não pode ser entendido como o único provedor do gasto social, responsável por repensar nas conseqüências das atividades antrópicas na

"Doutoranda em Direito Público na Universidade de Sevilla, Espanha. E-mail: vipgomes@hotmail.com. 
busca do equilíbrio ambiental. É necessária a tomada de consciência por parte dos três principais agentes de mercado: o Estado, o consumidor e a organizações empresariais.

As organizações empresariais são criadas para perdurar de forma ilimitada e sua sustentabilidade está diretamente ligada à sustentabilidade do sistema físico-social de que forma parte. Por outro lado é a instituição que tem a maior capacidade de inovação, e portanto, maior capacidade de contribuir para uma mudança positiva, transformando o capitalismo em algo mais humano.

Daí a preocupação da política ambiental da União Européia nos últimos anos e fundamentalmente a partir do V Programa Comunitário de 1993- 2000 incentivando o uso progressivo de instrumentos voluntários empresariais que complementem e até substituam paulatinamente a regulação direta e ao intervencionismo administrativo.

Atualmente existem inúmeras fórmulas que facilitam a auto-regulação empresarial para implantação de instrumentos de gestão ambiental que podem ajudar as empresas para que, a partir de suas próprias metas e princípios, sejam capazes de se adequar às necessidades do desenvolvimento sustentável. A implantação deste um sistema varia conforme procedimento e complexidade em função do tipo de sistema de certificação escolhido, tanto a nível europeu (EMAS) como internacional (ISO).

Portanto, este estudo se propõe a analisar a auto-regulação empresarial ambiental, bem como seu caráter econômico, examinando os modelos de gestão ambiental existentes adotados por empresas ambientalmente responsáveis, principalmente no que tange aos modelos mais usuais no âmbito da União Européia, quais sejam, o EMAS e a ISO 14000, e finalmente apontar suas vantagens e diferenças.

\section{AUTO-REGULAÇÃO EMPRESARIAL E CARÁTER ECONÔMICO DOS INSTRUMENTOS DE GESTÃO AMBIENTAL}

A auto-regulação empresarial em termos ambientais nasceu da conscientização de que a proteção ambiental não deve ser somente vista sob o prisma defensivo, apenas buscando soluções corretivas baseadas no estrito cumprimento da legislação, e passou a ser vista pelos empresários como uma necessidade.

Esta busca por uma auto-normatização ambiental foi iniciada pelas atividades industriais e de mineração, por serem mais visíveis e submetidas a controles mais rigorosos. Além destas, outras empresas que de alguma forma possuíam uma imagem ambiental negativa gerada pelo impacto causado pela comercialização do seu produto ao longo do tempo, ou aquelas corporações 
que precisavam recuperar sua imagem desgastada por acidentes ou incidentes recentes, passaram também a dar mais atenção às questões ambientais.

Esta tomada de atitude empresarial é conseqüência de uma própria demanda de mercado, onde o mundo globalizado passa compreender que o Estado não deve ser o único responsável pela demanda sócio-ambiental dos gastos, pois o setor empresarial, que segundo a World Investment Report da ONU em 2000 já representava mais de $35 \%$ do PIB mundial, possui grande responsabilidade com meio em que atuam.

Diversos setores empresariais começaram a perceber que adotar esta postura ambiental possui benefício duplo, ou conforme Lustosa (2003, p. 143) "duplo dividendo", se convencionou chamar de ecoeficiência, ou seja, produzir bens e serviços melhores reduzindo continuamente o uso de recursos e a geração de poluentes. Ademais, os benefícios alcançados com a destinação correta dos resíduos gerados e a eliminação de eventuais multas e penalizações causadas por uma má gestão ambiental, podem ser expressivos, mesmo em curto prazo.

Outro fator indutor do surgimento de iniciativas de auto-regulamentação empresarial está relacionado com as dificuldades encontradas na proteção de mercados nacionais por meio de barreiras comerciais após o Tratado de Marrakesh de 1994. Este Tratado encerrou a rodada Uruguai de negociações comerciais multilaterais no âmbito do General Agreement and Tariffs and Trade (Gatt) e criou a Organização Mundial do Comércio (OMC) e, entre outras consequências, exigiu o nivelamento dos custos de produção entre empresas produtoras de bens similares, situadas em países diferentes com diferentes exigências legais com respeito às questões socioambientais.

No entanto, alguns países diante das novas regras do comércio internacional, que eliminou barreiras tarifárias e regimes de quotas de importação, buscaram manter sua competitividade no mercado de outras formas, e assim, impuseram as chamadas "barreiras verdes" ou "dumping ambiental" para impedir a entrada de produtos da concorrência no país, muitas vezes de forma arbitrária ou injustificável. No entanto, este artifício de proteção contra concorrência é uma prática condenável ratificada por diversos países na Eco-92 no princípio 12 da Declaração do Rio, e vem também sido combatida na OMC.

A certificação ambiental vem, portanto, trazer vantagens para as empresas, tornando-as mais competitivas e compensando as dificuldades que enfrentam com os concorrentes ou até mesmo com os consumidores mais conscientes. Outras vantagens para a empresa são: à criação de uma imagem verde, acesso a novos mercados, redução ou eliminação de acidentes ambientais, evitando, assim, custos de remedição, incentivo ao uso racional de energia e dos recursos 
naturais, redução do risco de sanções do poder publico através de multas (muitas vezes representam a adequação a legislação vigente), assegurar aos clientes o compromisso com o gerenciamento ambiental demonstrável, satisfação dos critérios dos investidores e melhoria do acesso ao capital, facilidades na obtenção de licenças e autorizações, melhoria das relações entre governo e indústrias, prêmios de seguro mais baixos, taxa de juros reduzidas e facilidade de acesso à algumas linhas de financiamentos públicos e incentivos fiscais.

Não se trata apenas de aferir vantagens financeiras, mas também de evitar prejuízos, pois os acidentes e os crimes ambientais provocam escândalos corporativos que abalam a confiança dos investidores, consumidores e acionistas, refletindo-se em queda de vendas e, consequentemente, em prejuízo financeiro. Outro fator é o risco financeiro real de uma crise ambiental de grandes proporções, capaz de gerar escassez de matérias-primas e de fontes energéticas que suportam o atual padrão de produção industrial.

Vale lembrar que a implantação de instrumentos de gestão ambiental em uma empresa é criação do homem que vive numa realidade de busca incessante pelo lucro, ou seja, deve ser encarado como um mais investimento feito no contexto de economia de mercado, que só será exeqüível se a relação custo benefício for compensatória.

O princípio econômico que deve ser adotado pelas empresas é simples: o ótimo da degradação, segundo Bobbio (2004) é aquele no qual o custo ambiental não supera o custo imposto à sociedade pela redução de consumo maléfico ao meio ambiente gerado no processo produtivo.

Essa lógica objetiva internalizar para o setor empresarial um passivo ambiental que é externalizado para toda coletividade, de forma a obrigar os agentes poluidores a incorporar aquilo que seria lançado no meio ambiente em desfavor da sociedade e das pessoas, assumindo os custos e seus efeitos danosos, ou não o fazendo, pagando de alguma forma por isso.

Segundo Barbieri (2007) há alguns mecanismos econômicos capazes de induzir as organizações e os indivíduos a alterarem seu comportamento e sua postura em face do meio ambiente. Estes instrumentos podem ser de dois tipos: fiscais ou de mercado. Os fiscais se realizam mediante transferências de recursos entre os agentes privados e o setor público e podem ser subsídios ou tributos. Quanto aos instrumentos de mercado, estes se efetuam por meio de transações entre agentes privados em mercados regulados pelo governo, é o caso das permissões de emissões transferíveis, criadas a partir da fixação de níveis aceitáveis de poluição em diferentes períodos e da venda no mercado de títulos de certificados de permissões transferíveis de um determinado poluente. 
Diante da própria experiência e estrutura empresarial, os instrumentos econômicos têm uma maior flexibilidade para adequar à necessidade empresarial aos custos ambientais de internalização da sua produção, o que significa que posteriores políticas de comando e controle já serão implantadas com custo menor, uma vez que esta já estaria inserida na realidade do ambiente produtivo.

Outra discussão que se insere neste contexto é quanto à possibilidade de se fazer uma valoração econômica dos bens ambientais. Isto, pois, sabe-se que a atividade produtiva gera custos ambientais não conversíveis ao sistema de preços, além disso, o mercado não gera incentivos apropriados para o uso eficiente dos recursos naturais, os quais são tratados como recursos livres ou de custo muito baixo e continuam a ser superexplorados.

Para alguns autores, tal como o economista Matthos (2004, p. 17), o fundamento da valoração ambiental representa a base ideológica dos instrumentos econômicos de gestão ambiental:

O custo da degradação ambiental e do consumo dos recursos naturais não tem sido computados nos processos econômicos. Para que este processo econômico continue a ser produtivo um preço terá que ser pago. A valoração ambiental é essencial, caso se pretenda deter a degradação da grande maioria dos recursos naturais antes que ultrapasse o limite, fundadas num manejo integrado e sustentável dos da irreversibilidade.

De um outro lado os juristas, tal como Disep (2004, p. 94-95) se posicionam em sentido inverso:

Aos olhos dos economistas, o grande desafio que impera é o de atribuir valor monetário ao bem ambiental, para garantir-lhe papel de bem econômico e, por via de conseqüência, a sua manutenção no mercado. O que constitui, de certa forma, a contramão do Direito, que vem em onda oposta, buscando efetivar a indisponibilidade, legalmente, atribuída ao bem ambiental, até mesmo na sua concepção econômica, embora de forma gradativa e com a variável de uma atuação sustentável.

\section{RESPONSABILIDADE SÓCIO-AMBIENTAL DAS EMPRESAS}

As trajetórias em direção a adoção de estratégias ambientalmente sustentáveis diferem significativamente entre setores e entre empresas. Nas últimas décadas as inovações ambientais utilizadas nas empresas resultantes de regulamentações podem ser classificadas em duas categorias: a tecnologia end of pipe, que corresponde ao tratamento de resíduos, efluentes e emissões, ou seja, tem caráter apenas reparador, e a tecnologia pollution prevention, que resultam ações da 
empresa evitando que ocorra a poluição, constituindo numa tecnologia de caráter preventivo, e portanto, mais próximo do que se espera em termos de sustentabilidade empresarial.

Para Tarrega e Oliveira (2001) responsabilidade corporativa é fruto de confluências dos seguintes fatores: ecológicos, como a degradação ambiental insustentável das últimas décadas; sociológicos, como a percepção do consumidor em relação à responsabilidade social e ambiental das empresas; econômicos, como o aumento do valor das ações das empresas e os incentivos governamentais, e circunstanciais, como progresso tecnológico para o desenvolvimento sustentável.

Além do setor empresarial, enquanto consumidor de recursos naturais e produtor de resíduos, é importante a analisar à Sociedade enquanto consumidora destes produtos, e parte fundamental desta cadeia produtiva. A grande oferta de produtos e serviços nos mercados atuais gera cada vez mais nos consumidores, uma atenção maior quanto as característica dos produtos ou serviços prestados, portanto, estes consumidores, muitas vezes chamados de consumidores verdes, podem através de seu poder de decisão afetar significativamente na lucratividade das empresas.

Consumidores e ONGS de grande repercussão mundial como o Greenpeace, ou de uma forma mais ampla, os chamados "stakeholders", tem exigido produtos ecologicamente compatíveis e o mercado externo repudia, muitas vezes, transações com empresas que não tem um gerenciamento programado da questão ambiental. Caso a empresa ignore a importância que tem sido dada à responsabilidade corporativa, ela pode ter seus produtos e serviços vetados. Uma propaganda negativa decorrente de denuncias de mídia pode ser fatal para o capital reputacional de uma organização. Daí a utilização do instituto da governança corporativa como meio de conciliar essas responsabilidades com o crescimento da empresa.

Nos países desenvolvidos, onde a renda dos consumidores é elevada, eles exercem uma demanda por produtos ecologicamente corretos, mesmo sendo estes mais caros do que os tradicionais. Nos países em desenvolvimento, uma grade distância entre o grau de conscientização da população e pressão efetiva dos consumidores não estimulam as empresas a adotar produtos e processos menos agressivos ao meio ambiente.

Por outro lado, esta mudança do pensamento social deve ser cada vez mais encarada como um compromisso empresarial. Isto pois, a adoção de grande parte da empresas globais aos sistemas de certificação, levaria a disseminação de maiores informações sobre a origem da matéria prima e composição dos 
produtos, bem como o crescimento da tomada de consciência por parte da sociedade em geral e o maior número de consumidores verdes que poderiam optar por bens e serviços menos agressivos ao meio ambiente. Também os consumidores intermediários (empresas que compram insumos de outras empresas) devem ser induzidos a adotar práticas ambientalmente corretas por exigência de seus compradores, que deveriam passar a exigir de seus fornecedores a gestão ambiental em seus negócios.

Analisando este contexto de concorrência acirrada vigente no mercado mundial, não apenas as grandes corporações, mas todos os setores empresarias tem buscado definir sua política ambiental, demonstrando uma preocupação com o repudio dos consumidores em adquirir bens que ao longo do seu ciclo de vida causem degradação ambiental.

As empresas tem respondido a estes consumidores de diversas formas: definindo metas para redução das emissões, criando departamentos especialmente voltados ao meio ambiente e as relações corporativas, apoiando diretamente as ONGs, até criando suas próprias organizações em fins lucrativos e fundações, destinadas a gerenciar seus investimentos em projetos sociais.

É evidente que a implantação destes sistemas de gestão ambiental gera inúmeros custos para empresa tais como a gestão de resíduos e vertidos, vigilância e controle, melhoria de instalações, diversos tipos de assessoramento técnico, formação de profissionais e planos emergenciais.

Ao definir a sua política ambiental, a empresa declara suas intenções e princípios em relação ao seu desempenho ambiental, regulando sua estrutura de ação bem como os seus objetivos e metas ambientais. Esta política ambiental não deve ser entendida como elemento inibidor do desenvolvimento, mas sim como um dos seus instrumentos mais valiosos, ao propiciar a gestão racional dos recursos naturais.

Em suma, para as organizações que aderem aos novos conceitos de gestão introduzidos por estas normas, a questão ambiental deixa de ser um temaproblema, para tornar-se parte de uma solução maior - o correto posicionamento da empresa na sociedade, por meio do respeito ao meio ambiente e da qualidade e competitividade de seus produtos. 


\section{SISTEMA DE GESTÃO AMBIENTAL DA UNIÃO EUROPÉIA - EMAS}

\subsection{Marcos Históricos de Implantação dos Sistemas de Gestão Ambiental na Europa}

Ao largo dos últimos anos, como conseqüência do processo tecnológico de fabricação e desenvolvimento da competitividade dos produtos, surgiram mecanismos de assegurar a qualidade de produção empresarial. A partir de então as atuações neste campo seriam constantes. Em 1979 a Bristish Standard Institute publicou a primeira das normas de qualidade, a norma BS 5750, e em 1992 esta mesma instituição publicou a BS 7750 voltada para gestão ambiental.

Em 1991 se apresentou na Comissão Européia o primeiro esboço de um regulamento sobre auditorias e sistemas de gestão ambiental, que se aprovou definitivamente em 29 de junho de 1993 - Regulamento 1836 do Conselho Europeu - pelo qual se permitia que as empresas do setor industrial aderissem com caráter voluntário a um sistema comunitário de gestão e auditoria ambiental.

$\mathrm{Na}$ União Européia, alguns Estados Membros já contavam com certa tradição no tema antes de 1993, data de publicação do regulamento, como por exemplo Suécia, a França, a Holanda, o Reino Unido e a Irlanda. É conveniente lembrar que as primeiras normas da série ISO, conforme será analisado a seguir, só seriam lançadas em 1996.

Ao mesmo tempo, nascem, em um espaço curto de tempo, iniciativas internacionais públicas e privadas, e direta ou indiretamente voltadas à gestão ambiental empresarial, dentre as quais se destacam: a Declaração do Milênio, o Pacto Mundial das Nações Unidas, as linhas diretrizes da OCDE para Empresas Multinacionais, o Livro Verde da União Europeu, as Comunicações Européias sobre Responsabilidade Corporativa de 2002 e 2006, o Global Reporting Initiative e na mais recente comunicação da Comissão Européia sobre o tema, realizada no dia 22 de março de 2006, foi publicada a Aliança Européia para RSE, que conta com um anexo chamado "Fazer da Europa um Pólo de Excelência da Responsabilidade Social das Empresas”, e este é sem dúvida alguma, o cerne desta comunicação e principal objetivo da Comissão Européia.

Para Velasco Osma (2006), a União Européia tem a intenção de propor um enfoque baseado em ações mais profundas onde todos os agentes desempenhem um papel ativo, mas também é consciente que tal compromisso não deve ser considerado como substituto da regulamentação ou legislação destas matérias, instando os países não apenas europeus, mas também o resto do mundo, que não tenham desenvolvidas suas legislações, a instauração de um marco 
jurídico adequado a fim de desenvolver o fomento da Responsabilidade Social Empresarial.

\subsection{Sistema Gestão Ambiental da União Européia- EMAS}

O Sistema Comunitário de Gestão e Auditoria Ambiental da União Européia chamado EMAS - Environmental Management and Audit Scheme - foi criado no Quinto Programa Comunitário de Política Ambiental, através do Regulamento de Parlamento Europeu e Conselho 1836/1993 de 29 de junho. Este regulamento hoje se encontra derrogado pelo Regulamento CE 761/2001 de 19 de março. Conforme o art. 1 do referido Regulamento, possui dois principais objetivos: um de regular um sistema a nível europeu de caráter voluntário incentivando as empresas a adotarem mecanismos de gestão ambiental, e o outro de proporcionar informação e dar publicidade sobre o comportamento das organizações para o público e outras partes interessadas.

Inicialmente pelo Regulamento CE 1836/1993, este sistema de gestão ambiental tinha aplicação exclusiva ao setor industrial, no entanto, já na primeira revisão feita pela Comissão em 1998, foram feitas mudanças neste sentido, e passou a ser usado o termo "organização" no sentido de englobar empresas, entidades e instituições, superando o conceito limitado de empresa usado até então, ou seja, podendo contemplar incluso instituições e administrações públicas.

Ressalta Seonez Calvo e Ângulo Aguado (1999) que esta modificação torna o EMAS muito mais parecido à forma de aplicação da ISO 14.000, facilitando adaptação das empresas à este sistema. Sobre esta questão, alerta a espanhola Mora Ruiz (2007, p. 214):

A regulação do EMAS deve proporcionar a integração de sua norma com os sistemas de certificação de caráter privado, de maneira que estes possam ser o passo prévio para obter a validação da declaração ambiental, de forma também que os Estados Membros evitem a duplicidade de controles.

Se por um lado, o EMAS, além de cumprir seu papel de instrumento de mercado, também atua como um instrumento de controle dos comportamentos das empresas com repercussão ao meio ambiente, por outro, também expressa o princípio da prevenção, ao cumprir a função de acreditar a organização um mínimo nível de qualidade ambiental, atuando como um elemento de proteção ambiental de caráter globalizador e integrador e incitando que outras empresas da mesma cadeia produtiva também estejam imbuídas do compromisso de promover a gestão ambiental conforme seu regulamento.

Para Mora Ruiz (2007), o EMAS representa a concretude do conceito de 
desenvolvimento sustentável, na medida em que rentabiliza o cumprimento de requisitos ambientais de forma superior ao exigido legalmente, sem, no entanto, deixar de lado seu contexto de mercado, onde o público e as outras empresas dispõe de um fluxo contínuo de informações que permitem uma comparação conforme as regras de oferta e demanda.

O fundamental atrativo destes sistemas de gestão, como já abordado anteriormente, é seu aspecto voluntário, ou seja, cada organização tem a liberdade de em aderindo ao sistema, definir sua política ambiental (conforme Art. 2 do Regulamento CE 761/2001), bem como os resultados que pretendem alcançar. No entanto, toda organização deve seguir os padrões definidos no anexo do regulamento, de forma que esta autonomia não represente o risco de tanta divergência quanto ao grau de cumprimento de objetivos ambientais por parte de diferentes organizações em função dos distintos compromissos contraídos por cada organização.

Na opinião de Calvo e Aguado (1999, p. 154):

A nova tendência vem marcada pela voluntariedade de certos aspectos normativos particulares e pela auto-regulação das empresas em função das novas necessidades e exigências de mercado. Por outro lado, a administração intervém estabelecendo uma legislação ambiental básica, que desenvolve os requisitos mínimos a cumprir por produtos e empresas, a fim de garantir a proteção ambiental.

Esta responsabilidade de caráter ativo da organização pode ser compensada por uma menor intervenção e controle por parte da administração. Ademais, esta autonomia dada pelo EMAS pode ser entendida como uma vantagem para que seja mais difundido o sistema e represente também o que convencionalmente se chama de responsabilidade compartida, no sentido de que cabe não só ao Poder Público, mas também as empresas promover a tutela ambiental criando seus próprios mecanismo de regulação ambiental e de autocontrole.

Durán Romero (2007, p. 246) utiliza o termo Administração Pública "não subjetivada”, para fazer referência ao fenômeno de satisfação dos interesses gerais mediante a participação ativa de sujeitos particulares através de sua própria atividade econômica, sempre e quando se conceda transigência pública ao resultado da mesma, nos situando em termos de auto-regulamentação, que é um fenômeno de maior envergadura que a mera colaboração.

Quanto à sua operacionalização, o EMAS estabelece um duplo procedimento de verificação e controle da eficácia do Sistema de Gestão Ambiental: primeiro mediante a a realização de auditorias periódicas e depois mediante a validação de um verificador ambiental acreditado. Assim, o EMAS introduz uma nova 
figura, o verificador ambiental (Art. 2. q do regulamento ), que atua por cima do auditor (Art. 2.n do regulamento). O auditor se ocupa em auditar internamente o sistema de gestão ambiental implantado na organização, enquanto, o verificador, ambiental se encarga de verificar a conformidade deste sistema e de validar a declaração ambiental, elaborada pelo centro industrial.

Diferente dos auditores, os verificadores devem estar acreditados por organismo de verificação nomeados pelos Estados Membros e devem demonstrar sua competência, formação, experiência, independência e imparcialidade. Um requisito fundamental é que o verificador sempre deve ser independente do auditor.

A presença dos verificadores supõe que a Administração não examina, avalia ou controla diretamente o agente contaminador, mas que não há duvida que dirija suas faculdades de supervisão a estes verificadores, através de outros atores como os organismos competentes e organismos de acreditação (Art. 2.u e Art. 2.r do Regulamento 761/2001, respectivamente), que por sua vez, são organizações imparciais designadas pelos Estados Membros para desempenhar as funções definidas para o sistema de acreditação.

Estes organismos promovem o fenômeno da normalização, na medida em que estabelecem critérios de caráter técnico conforme os quais desenvolvem a atividade em questão, sem que, no principio, haja a intervenção direta da administração na criação dos referidos critérios, favorecendo, assim, a existência de uma certa autonomia. As entidades de acreditação se convertem em interlocutores da Administração e chegam a executar certas funções públicas, mesmo assim continuam submetidas ao controle da Administração.

O EMAS obriga a realização de auditorias ambientais periódicas, mas exigem que estas estejam seguidas de sua correspondente declaração ambiental como método de comprovação da eficácia da gestão ambiental da indústria. Este documento ambiental adquire a transigência pública no momento em que se obtém a validação, o qual é requisito imprescindível, como regra geral, para a inscrição no registro de organizações, utilização de logotipo e correspondente publicidade.

Feito isto, se estará cumprindo a segunda finalidade do Sistema Comunitário de Gestão e Auditoria Ambiental, que representa a consolidação dos direitos de acesso à informação ambiental dos cidadãos em geral, e nestes, em especial aos seus trabalhadores, assim como representa um diálogo com este público consumidor no contexto de mercado.

Uma das principais causas da pouca difusão do sistema, ao menos em suas etapas iniciais, foi à lentidão com que a maioria dos Estados Membros 
abordaram a tarefa de estabelecer a infra-estruturar necessária para sua a aplicação, principalmente com respeito aos cinco agentes implicados: organismos competentes, autoridade responsável competente, entidades de acreditarão, auditores ambientais, e verificadores ambientais acreditados.

\section{SISTEMA DE GESTÃO AMBIENTAL INTERNACIONAL - ISO}

A International Standard Organization (ISO) é uma organização internacional não governamental, sem fins lucrativos, com sede em Genebra, na Suíça, cujos membros são entidades normativas de âmbito nacional provenientes de mais 150 países, que fornecem informações, juntamente com os demais setores interessados, visando promover e facilitar as trocas internacionais de mercadorias e serviços.

A ISO possibilitou, por meio da criação de padrões técnicos aceitos internacionalmente, minimizar as barreiras tecnológicas que limitavam as transações comerciais em todo o mundo, facilitando os processos de importação e exportação. É a norma de certificação mais abrangente porque é aplicável a todos os tipos e tamanhos de organizações. Tem, portanto, caráter privado, e todas as suas normas, aprovadas por consenso, são voluntárias, ou seja, sua adesão não acontece por força de lei.

O sistema ISO adquiriu conceituação global com em 1976, com a normatização de padrões de gestão e qualidade, quando foi criado um grupo de trabalho que culminou com as normas para gestão da qualidade e sistemas de garantia da qualidade - a ISO 9000.

Antes de uma norma ser promulgada, e após a sua aprovação, cada país membro adota a norma com sua versão nacional. No Brasil, a representante na ISO é a ABNT - Associação Brasileira de Normas Técnicas e o INMETRO é o organismo de certificação membro do IAF, reconhecido internacionalmente, o qual credencia o Organismo de Certificação Credenciado. Vinculados ao Inmetro existem 19 Organismos de Certificação, sendo a maioria deles filias de multinacionais européias espalhadas por todo mundo.

Diante da proliferação das normas ambientais em todo o mundo, em 1991 a ISO criou o grupo de ações estratégias para o meio ambiente, o SAGE - Strategic Action Gruop on the Enviroment. Em 1993 foi constituído um comitê técnico, o TC 207, incumbido de elaborar normas internacionais que assegurassem uma abordagem sistêmica à gestão ambiental e possibilitassem a certificação ambiental de organizações e de produtos, aumentando a capacidade da organização de alcançar e medir melhorias no desempenho ambiental. Deste trabalho, nasceu a série ISO 14000 que foi criada para ser aplicada tanto às atividades industriais como às atividades extrativas, agroindústrias e de serviços. 
A ISO 14000 advém da necessidade de nivelar as normas internacionais de cunho ambiental, ajudando também a transpor as barreiras ambientais no mercado de comércio exterior e padronizando medidas preventivas no processo de exportação. É a série que se propõe a servir como guia para que as empresas possam criar documentar, programar e manter um sistema efetivo de gestão empresarial que além de reforçar o cumprimento da legislação ambiental.

Cabe a ISO 14000 dar as diretrizes para o estabelecimento e a revisão dos objetivos e metas ambientais, incluindo o comprometimento com a prevenção da poluição (sólidos, líquidos, gasosos, ruídos); com a melhoria contínua e com o atendimento à legislação e normas ambientais aplicáveis. Além disso, para reforçar sua implantação, deve estar disponível ao público, documentada e comunicada a todos os empregados.

Vale ressaltar que, assim como o EMAS, não substitui o cumprimento às legislações ambientais locais, pelo contrário, a ISO propugna pela obediência à toda legislação ambiental que tenha efeito sobre o referido local. Sobre esta questão Calvalcantti Filho (2002, p. 104) comenta:

Um dos pontos mais relevantes da certificação ISO 14000 é este pertinente ao integral atendimento das exigências legais por parte da organização. Como conseqüência objetiva direta, temos a diminuição das autuações por infração à legislação ambiental, reduzindo-se os custos da empresa com pagamento de multas e ou condenações em processos judiciais.

Uma importante característica da ISO 14000 é a sua flexibilidade no sentido de que ao mesmo tempo em que mantém compatibilidade com a ISO 9000, facilitam a implementação em empresas que estão em consonância com esta série, possibilita a sua adoção por empresas que não tenham adotado a ISO 9000. Sobre esta questão se manifesta Disep (2004, p. 154):

Tanto a ISO série 9000 como a série 14000 tiveram por fim o desenvolvimento de processos, ou seja, de aspectos de uma padronização e não da padronização em si de produtos, o que seria impossível dado o fato da diversidade de produtos existentes no mercado. Portanto, implicou a elaboração de estruturas, criação de terminologias, critérios de auditorias e outros elementos que foram criados, para tornar pelo menos compatíveis os padrões de gestão. A nosso ver, cria, na realidade, uma linha política empresarial comum.

A ISO 14001 é a norma da série que orienta para a certificação ambiental, e reza que para se alcançar tal certificação precisa ao menos ter implantado um Sistema de Gestão Ambiental (SGA), cumprir a legislação ambiental aplicável ao local da empresa, e assumir um compromisso de melhoria contínua de seu desempenho ambiental. Ademais para que este certificado tenha validade 
é necessário que este procedimento seja feito por uma entidade especializada e independente, reconhecida em um organismo autorizado de acreditação ou credenciamento.

O caminho a ser percorrido, revelando os seus requisitos, resume-se: na elaboração da política ambiental, no planejamento, na implementação e operação, na verificação e ação corretiva, na análise crítica pela administração que não cessa, devendo retornar no sentido de uma espiral em constante movimento, sendo a obrigatoriedade quanto à melhoria contínua o seu propulsor, movimentador.

Para tanto, primeiramente deve ser analisada a Política Ambiental da empresa, consubstanciados nos princípios gerenciais da organização somados aos objetivos, metas e procedimentos de controle para que após a organização possa se submeter à auditoria ambiental que deve comprovar sua conformidade com esta política ambiental adotada pela empresa, bem como com a legislação vigente.

As organizações que buscam na qualidade ambiental um fator de sucesso para se posicionar no mercado internacional, utilizam as normas da ISO 14000 para se valorizar. Contudo, Valle (2002, p. 134-139) adverte:

Não se trata de uma coletânea de normas técnicas ambientais (estas são elaboradas pela $\mathrm{ABNT}$ ) e sim se trata de sistema de normalização que ao mesmo tempo em que protege as organizações responsáveis contra concorrentes predadores que não internalizam alguns dos custos de seus produtos e serviços, que acabam sendo arcados pela sociedade, também pode ser um sistema nefasto se for utilizado para abrigar nas suas entrelinhas, interesses corporativos e mecanismos de proteção comercial.

Segundo o Inmetro existem hoje 726 empresas certificadas pela ISO 14000. Esta quantidade de empresas certificadas no Brasil quer dizer que seja pela complexidade do sistema de gestão, ou seja pelo seu elevado custo, apenas as empresas de grande porte a obtiveram, geralmente as que se encontram nos Estados mais industrializados.

\section{PRINCIPAIS DIFERENÇAS ENTRE OS SISTEMA EMAS (EUROPEU) E O SISTEMA ISO (INTERNACIONAL)}

Cada organização pode escolher diante de diversos fatores (tipo de empresa, âmbito de proteção européia ou internacional, situação ambiental ou necessidades) entre um ou outro programa de certificação, no entanto, cabe à Comissão Européia comprovar o conteúdo das normas européias e internacionais, ou outras formas de certificação de sistemas de gestão ambiental 
buscando uma possível integração destes sistemas ao EMAS. Na prática, fundamentalmente as normas ISO 14000 se aproximam e tem conseguido a integração como forma de superar a inicial situação de competitividade entre um sistema e outro.

E como sistemas mais usuais e competitivos a nível de mercado mundial, necessário se faz analisar brevemente as dificuldades, vantagens e principais diferenças entre estes dois sistemas.

As dificuldades para implantação de um sistema de gestão ambiental segundo o EMAS ou segundo a ISO 14001 são similares, pois o desenvolvimento do sistema além de custoso, também é bastante lento, requerendo esforços conjuntos de toda organização, de forma que todos os departamentos, setores, coordenadores e diretores. Por outro lado, são inúmeras as vantagens apontadas pela implantação de um sistema de certificação, e seja através do EMAS ou ISO 14001, senão vejamos: cumprimento da legislação, economia de custos, melhora das relações externas, melhora de imagem e aumento das vendas e etc. Quanto às diferenças entre um e outro sistema, pode-se afirmar elas ocorrem basicamente em razão da estrutura dos documentos, seu âmbito de aplicação e conceituação de política ambiental.

Assim, enquanto um regulamento (EMAS, Regulamento 1836/1993) é valido apenas no âmbito comunitário, o outro é uma norma de âmbito internacional (UNE_ISO 14001) e por isso mesmo, a ISO goza de mais prestigio internacional e tradição, no entanto, por se tratar de uma norma internacional está dotada de um caráter mais generalista. O EMAS, por outro lado, dispõe de reconhecimento oficial por parte da Administração Européia, ainda que conte com menos tradição no setor da certificação e seu âmbito geográfico de aplicação seja mais restrito.

O conceito de política ambiental, bem como ao conteúdo da revisão desta política, são similares em ambos os sistemas, sem embargo, o EMAS é mais exigente, pois estabelece uma série de aspectos e princípios de atuação que a organização devera tomar em consideração na hora de relatar sua política ambiental. Enquanto isso, na ISO 14001, os requisitos estipulados para o estabelecimento da política ambiental são menores.

Por outra parte, o EMAS exige a manutenção de um registro interno dos efeitos ambientais significativos, enquanto que a ISO 14001 requer o estabelecimento e a atualização de um procedimento para identificar os aspectos ambientais a fim de determinar quais tem impactos significativos, mas no entanto, não exigem seu registro. 
Ademais, como já dito anteriormente, o EMAS cria uma nova figura que não existe no programa de ISO 14001, o verificador ambiental acreditador, independente e neutro que atua acima do auditor, validando e acreditando o sistema e assegurando assim, a credibilidade do sistema de gerenciamento ambiental.

Todas estas diferenças, no levam a concluir que no geral EMAS é bastante mais exigente respeito de certos elementos que ISO 14001 e isto provocou uma certa incompatibilidade entre ambos sistemas. Pensando neste impasse, o Comitê Europeu de Normalização (CEN) elaborou um documento que se chama “ Documento Ponte de Uso das Normas ISO 14001, 14011, 14012” para as empresas que querem registrar-se em EMAS, detalhando os 14 pontos de diferença básicos entre ambos sistemas, facilitando assim o acesso das empresas, certificadas segundo ISO 14001 ao EMAS.

\section{CONCLUSÃO}

Ser socialmente e ambientalmente responsável não significa apenas cumprir com as obrigações jurídicas, mas também ir mais adiante de seu cumprimento investindo mais em capital humano, o entorno e nas relações com os interlocutores.

Por outro lado, o mundo globalizado já entende que a adoção de medidas ambientalmente corretas por parte das empresas é uma questão de que envolve competitividade e sobrevivência, ou seja, tal como uma estratégia de mercado, onde os custos de adesão ao sistema de gestão ambiental num primeiro momento podem ser alto, mas assim mesmo, deve ser incentivado pois fatalmente resultará em acréscimos financeiros a longo prazo.

Justamente por não se tratar de procedimento nem fácil, nem barato que a a via de sua mais fácil implantação é a voluntária, sendo esta voluntariedade nota definitiva e característica de Responsabilidade Social Corporativa.

Neste contexto, a Política Ambiental da União Européia, nos últimos anos, fundamentalmente, a partir do V Programa Comunitário de Política e Atuação em matéria de Meio Ambiente e Desenvolvimento Sustentável (1993-2000), se caracterizou por um distanciamento progressivo do tradicional conceito de ordem e comando e por um impulso paralelo dos instrumentos voluntários.

É inegável que a disseminação da prática da gestão ambiental contribui para a maior conscientização ambiental e maturidade da sociedade com relação ao tema ambiental, gerando efeitos positivos no comportamento das organizações, nos empregados imbuídos com processo de certificação e na comunidade ao redor que passam também a ser inseridos neste programa de educação ambiental. 
O que não se pode esquecer é que ausência ou a deficiência dos processos de gestão poderá causar a deterioração e mesmo destruição das condições de existência e perpetuação do homem, donde se deve adicionar a essa análise valores que levem em consideração critérios dados não apenas pelo mercado, mas sobretudo, pela ciência, e que igualmente pugnem pelo estabelecimento de uma validade não utilitária e intrínseca da biodiversidade.

A sociedade econômica pleiteia o neoliberalismo com o fito de minimizar fatores de risco para sobrevivência da humanidade. Apenas através da mobilização social é que poder-se-á usufruir, utilizando a expressão kantiana, o direito cosmopolita, que tornará o homem cidadão do mundo, revelando uma maior solidariedade entre os povos na resolução de problemas em comum.

\section{REFERÊNCIAS}

BARBIERI, José Carlos. Gestão Ambiental empresarial: conceitos, modelos e instrumentos. 2 ed. e atual e ampl. São Paulo: Saraiva, 2007.

DISEP, Clarissa Ferreira Macedo. Direito Ambiental Econômico e a ISO 14000: análise jurídica do modelo de gestão ambiental e certificação ISO 14001. São Paulo: Revista dos Tribunais, 2004.

DURÁN ROMERO, Gemma. Empresa y médio ambiente: políticas de gestíón ambiental. Madrid: Pirámide, 2007.

LOZANO CUTANDA, Blanca; ALLI TURRILLAS, Juan Cruz. Administración y Legislación Ambiental. Madrid: Dykinson, 2006.

LUSTOSA, Maria Cecília. Economia do Meio Ambiente: teoria e prática. Rio de Janeiro: Elselvier, 2003.

MATTHOS, Katty Maria da Costa; MATTHOS, Arthur. Valoração econômica do Meio Ambiente: uma abordagem teórica e prática. São Carlos: Rima, Fapesp, 2004.

MORA RUIZ, Manuela. La gestión ambiental compartida: función pública y mercado. Valladolid: Lex nova, 2007.

NAVARRO GARCÍA, Fernando. Responsabilidad social corporativa: teoria y prática. Madrid: Esic, 2008.

NIETO SOLÍS, José Antonio. La Unión Europea: una nueva etapa en la integración económica de Europa. Madrid: Pirámide, 2005. 
OLCESE, Aldo; ÁNGEL RODRIGUEZ, Miguel. Manual de La empresa responsable y sostenible conceptos, ejemplos y herramientas de La responsabilidad social corporativa o de la empresa. Madrid: McGraw-Hill Interamericana, 2008.

SEONEZ CALVO, Mariano; ANGULO AGUADO, Irene. Manual de Gestión Medioambiental de la Empresa: sistemas de gestión medioambiental, auditorias medioambientales, evaluaciones de impacto ambiental y otras estrategias. Madrid: Mundi-prensa 1999.

TACHIZAWA, Takeshy. Gestão ambiental e responsabilidade social corporativa: estratégias de negócios focadas na realidade brasileira. 4. ed. rev e ampl. São Paulo: Atlas, 2006

TARREGA, Maria Cristina V. B.; OLIVEIRA, Bruno Gomes. Responsabilidade Corporativa, meio ambiente e desenvolvimento sustentável. In: TARREGA, Maria Cristina V. B. (Org.). Direito Ambiental e desenvolvimento sustentável. São Paulo: RCS, 2007.

VALLE, Cyro Eyer do. Qualidade Ambiental: ISO 14000. 4. ed. rev. e ampl. São Paulo: Editora Senac, 2002.

VELASCO OSMA, José. Fundamentos de la responsabilidad social y corporativa y su aplicación ambiental. Madrid: 2006. (Cuadernos del departamento de Derecho Ambiental del ICAM),

VERCHER NOGUERA, Antônio. Derecho Europeo Medioambiental: la protección del medio ambiente en la Unión Europea: aspectos críticos. Madrid: Consejo General de Poder Judicial, Centro de Documentación Judicial, 2008.

Artigo recebido em 16/03/09 e aceito em 06/07/09 